$\xi=$

\title{
Poronia radicata Hembrom, A. Parihar \& K. Das, A new record from Maharashtra State, India
}

\author{
Patil Anjali Rajendra , * Patil Ketaki Prakash \\ Department of Botany, Rajaram College, Kolhapur,Maharashtra, Kolhapur- 416004 \\ *Corresponding author E-mail: ketupatil90@ gmail.com
}

\begin{abstract}
Family Xylariaceae is represented from India by 187 species belonging to 12 genera till date. Genus Poronia Willdenow ex SF Gray was reported for the first time from Kolkata in 2013. During the present mycological exploration, the species Poronia radicata Hembrom, A. Parihar \& K. Das, a coprophillous member of family Xylariaceae was collected and studied. This is the second report from the Indian sub-continent and first from state of Maharashtra, India. Thus, it makes a new report to the fungi of Maharashtra.
\end{abstract}

Keywords: Maharashtra; Mycotaxonomy; Poronia; Xylariaceae.

\section{Introduction}

The genus Poronia Willdenow ex SF Gray is a coprophillous member of Xylariaceae that encompasses small, black, nail- like fungi (Rogers, 1979). It is characterized by long, underground, branched, rooting base; terminally branched stroma; cup-shaped, stipitate, perithecia; upper surface of stroma membranous, carbonaceous- black; asci cylindrical, eight spored; sporidia ellipsoid, brown, fimicolous. The species was reported for the first time in India from Howrah (West - Bengal). Present work describes it for the first time from Maharashtra State.

\section{Material and methods}

Fresh material was collected during rainy season; preserved by drying in oven and in $4 \%$ formalin; detail structures and microphotography was done using research microscope and routine laboratory techniques; photographs were taken using Nikon digital camera; material was deposited in National Fungal Culture Collection of India, ARI Pune, M.S. and accession number obtained; SEM were obtained from Physics Department, Shivaji University, Kolhapur.

\section{Result}

Poronia radicata Hembrom, A. Parihar \& K. Das (Text Plate1: Fig. a - e; Plate 1: Fig. a - g)

Ascostroma stipitate, simple or branched, upper fertile part is disc shaped, supporting stalk holds heads and underground rooting bases. Height of the stroma is upto 1.5 to $3.5 \mathrm{~cm}$, fertile head is $2 \mathrm{~mm}(-10 \mathrm{~mm}) \times 2(-6) \mathrm{mm}$. Ascostroma is glossy and crusty, black (like charcoal) on the outer side and whitish within. Upper surface of the fertile part is rough due to perithecial openings; after drying- black, crusty, sometimes wrinkled. Perithecia globose to slightly elongated, on the upper part of the peltate disc, sunken below the thin black crust, $400(-700) \times 300(-350) \mu \mathrm{m}$.
Asci- eight spored $35(-42)$ x $5(-7) \mu \mathrm{m}$ arranged in uni-seriate manner, cylindrical, stipitate, spore bearing. Ascospores 7.5 × 5 $\mu \mathrm{m}$, hyaline to dark in colour, rounded germ pore is present. $\mathrm{Pa}$ raphyses $80(-150) \times 3(-5) \mu \mathrm{m}$, hyaline and septate.

Habitat: On dung, Gargoti, Dist. Kolhapur, M.S., India, $10^{\text {th }} \mathrm{Au}-$ gust, 2014, Anjali R. Patil, deposited in National Fungal Culture Collection of India, ARI, Pune, A.M.H. No. -9663.

\section{Discussion}

The genus Poronia Willd. ex Gray, was erected to accommodate the taxa with "black carbonous perithecia embedded in a white fleshy hemi- spherical or discoid stroma, borne on a long or short stipe" (Ahmad, 1946; Hembroom, et.al. 2013). Poronia differs from its allied genera Xylaria and Podosordaria by its stalked stroma with capitate to flattened disc with embedded perithecia (Dennis, 1957a and b; Rogers, 1979; Hembroom, et.al. 2013). Poronia is characterized by upright stipitate fruit bodies; fertile part in the form of capitate to flattened disc on stalked stroma; stromata simple or branched; perithecia embedded in fertile parts, elevations evident or lacking; asci stalked, cylindrical with welldeveloped apical ring becoming blue in Melzer's reagent; ascospores light to dark brown, asymmetrical, one-celled or unequally two- celled due to presence of hyaline cellular appendage with a short to long conspicuous or inconspicuous germ slit (Dennis, 1957 a and b; Hembrom, A. Parihar and K. Das (2013) described a new species Poronia radicata, from Aacharya Jagadish Chandra Bose Indian Botanic Garden, Howrah, West Bengal, India. This species is characterized by long underground branched rooting base, terminally branched stromata, capitate with an expanded and flattened stromatal disc, absence of paraphyses and apical germ pore (at maturity) and comparatively small sized ascospores with rounded apical germ pore. Its comparison with the present specimen corresponds well, hence described as Poronia radicata Hembrom, A. Parihar \& K. Das. (2013). It makes a new record to the fungi of Maharashtra. 
Text Plate.1: Poronia radicata Hembrom, A. Parihar \& K. Das.
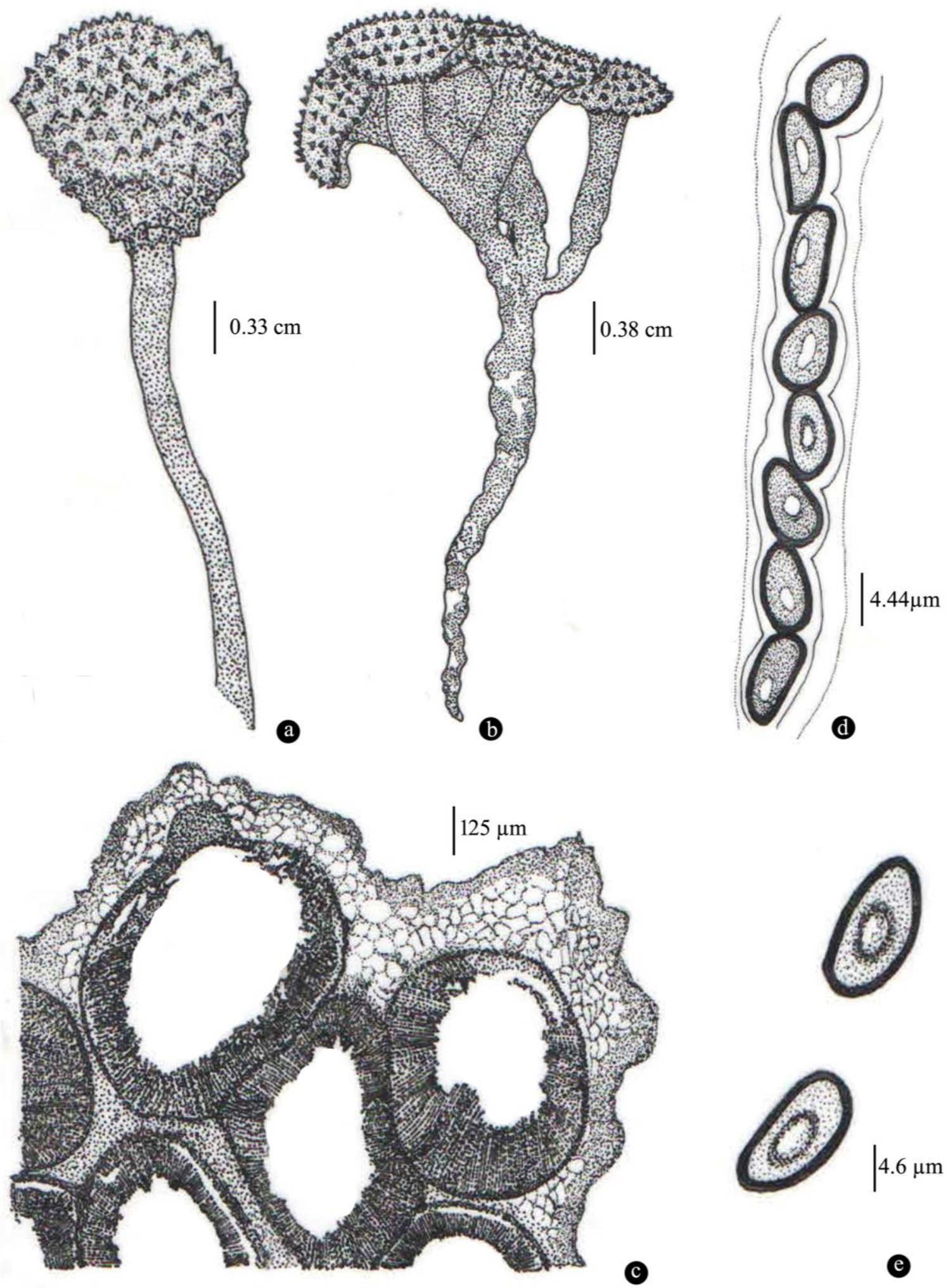

Fig. 1: a) Single Ascostroma. b) Branched Ascostroma. c) Perithecia. d) Ascus. e) Ascospore, Scale Bar=1 cm. 
Plate no. 1: Poronia radicata Hembrom, A. Perihar \& K. Das.

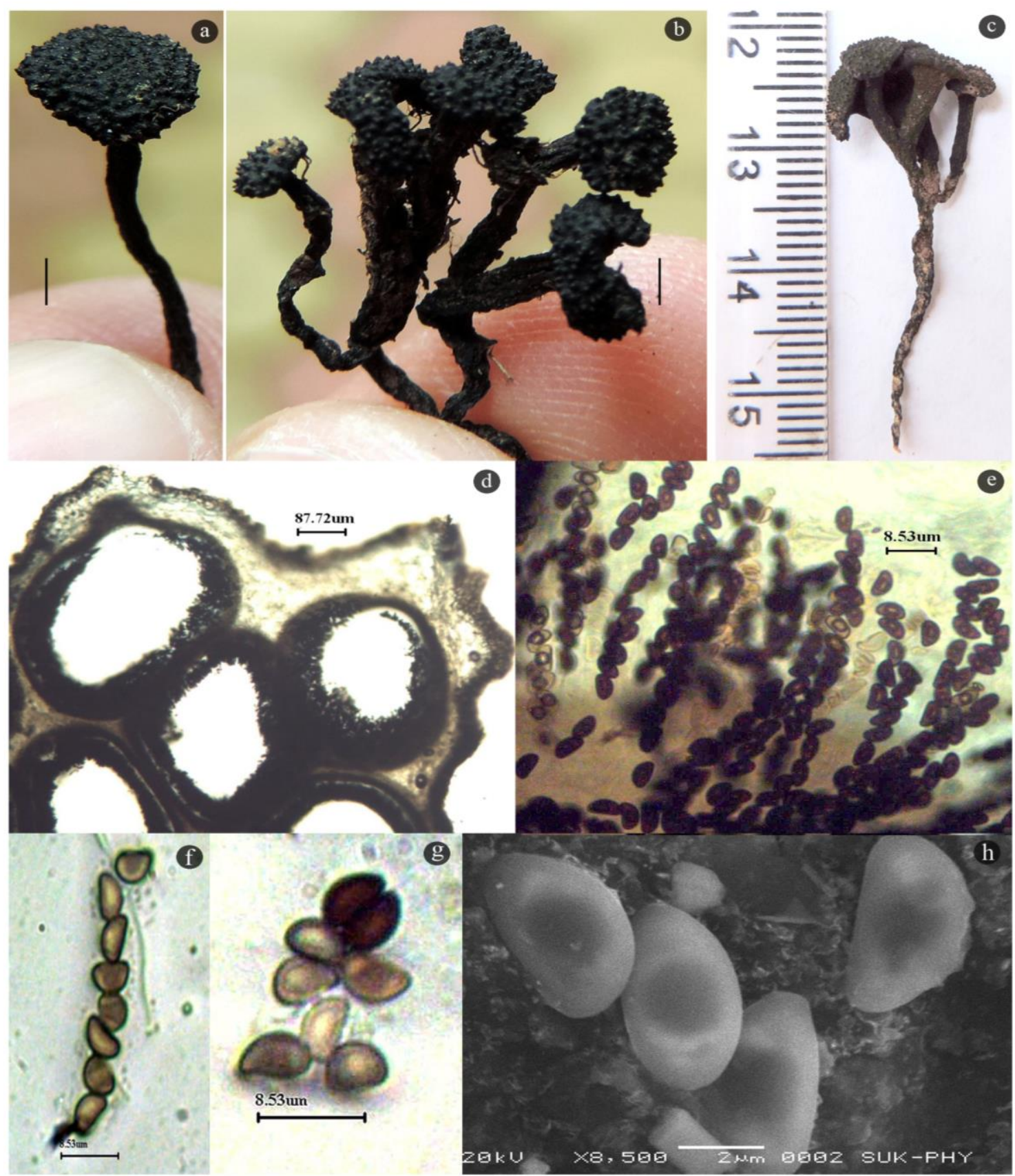

Fig. 2: (a-c) Single and branched Ascostroma, capitate head and rooting base. d) Papillate perithecia. e) Asci and Paraphysis inside the Perithecium. f) Single Ascus. (g-h) Ascospores. Scales a to $\mathrm{c}=1 \mathrm{~cm}$.

\section{References}

[1] Ahmad S (1946) The genus Poronia in India. Llyodia 9(2), 139143.

[2] Bilgrami KS, Jamaluddin \& Rizwi MA (1991) Fungi of India; List and References. Today and tomorrow's Printers \& Publishers, New Delhi, 798pp.

[3] Dennis RWG (1957a) Some Xylarias of Tropical America. Kew Bulletin 1, 401-444.

[4] Dennis RWG (1957b) Further notes on tropical American Xylariaceae. Kew Bulletin 2, 297-333.

[5] Hembrom ME, Parihar A \& Das K (2013) A new Species of Poronia from India. Current Reserch in Enviromnment and Applied Mycology 3 (2):182-185.

[6] Jamaluddin, Goswami MG \& Ojha BM (2001) Fungi of India, Scientific Publication (India) Jodhpur, $326 \mathrm{pp}$.

[7] Lohmeyer TR and Benkert D (1988) Poronia erici a new Spcies of Xylariaceae (Ascomycetes). Mycologia. 54(1), 93-102.

[8] Pande A (2008) Ascomycetes of Peninsular India. Scientific Publishers, Jodhpur. 584pp.
[9] Rawla GS \& Narula A.M (1983) Poronia pileiformis (Berk.) fr: A new record from India Current Science, 52(20), 990

[10] Richardson MJ (2001) Coprophilous fungi from Brazil. Brazilian Archives of Biology and Technology An International Journal. 44(3), 283-289.

[11] Rogers JD (1979) The Xylariaceae: Systematic, Biological and Evolutionary aspects. Mycologia. 71(1), 1-42.

[12] Rosariomedel \& Morales O (2013) New Ascomycete records from Guatemald, Mycotaxon. 124, 73-85.

[13] Suwannasai N, Whalley MA, Whalley AJS, Thienhirun S \& Sihanonth P (2012) Ascus apical apparatus and ascospore characters in Xylariaceae.International Mycological Association Fungus. 3(2), 125-133.

[14] Whalley AJS (1996) The xylariaceous way of life. Mycologia. 100, 897-922. 